\title{
Early-life origins of chronic respiratory diseases: understanding and promoting healthy ageing
}

\author{
Silvia Carraro' ${ }^{1}$ Nienke Scheltema ${ }^{2}$, Louis Bont ${ }^{2}$ and Eugenio Baraldi ${ }^{1}$ \\ Number 4 in the series "Multimorbidity and the lung" \\ Edited by L.M. Fabbri and J.M. Drazen
}

Affiliations: 'Women's and Children's Health Dept, University of Padua, Padua, Italy. ${ }^{2}$ Dept of Pediatrics, University Medical Center Utrecht, Utrecht, The Netherlands.

Correspondence: Eugenio Baraldi, Women's and Children's Health Dept, Unit of Respiratory Medicine and Allergy, Via Giustiniani 3, 35128 Padova, Italy. E-mail: baraldiđpediatria.unipd.it

ABSTRACT Chronic obstructive respiratory disorders such as asthma and chronic obstructive pulmonary disease often originate early in life. In addition to a genetic predisposition, prenatal and early-life environmental exposures have a persistent impact on respiratory health. Acting during a critical phase of lung development, these factors may change lung structure and metabolism, and may induce maladaptive responses to harmful agents, which will affect the whole lifespan.

Some environmental factors, such as exposure to cigarette smoke, type of childbirth and diet, may be modifiable, but it is more difficult to influence other factors, such as preterm birth and early exposure to viruses or allergens.

Here, we bring together recent literature to analyse the critical aspects involved in the early stages of lung development, going back to prenatal and perinatal events, and we discuss the mechanisms by which noxious factors encountered early on may have a lifelong impact on respiratory health.

We briefly comment on the need for early disease biomarkers and on the possible role of "-omic" technologies in identifying risk profiles predictive of chronic respiratory conditions. Such profiles could guide the ideation of effective preventive strategies and/or targeted early lifestyle or therapeutic interventions.

@ERSpublications

Early-life factors have a role in onset of asthma and COPD; early postnatal interventions may promote lung health http://ow.ly/BvUrx

Previous articles in this series: No. 1: Faner R, Cruz T, López-Giraldo A, et al. Network medicine, multimorbidity and the lung in the elderly. Eur Respir J 2014; 44: 775-788. No. 2: Divo MJ, Martinez CH, Mannino DM. Ageing and the epidemiology of multimorbidity. Eur Respir J 2014; 44: 1055-1068. No. 3: MacNee W, Rabinovich RA, Choudhury G. Ageing and the border between health and disease. Eur Respir J 2014; 44: 1332-1352.

Received: May 072014 | Accepted after revision: Sept 022014 | First published online: Oct 162014

Conflict of interest: Disclosures can be found alongside the online version of this article at erj.ersjournals.com

Copyright @ERS 2014 


\section{Introduction}

Complex chronic respiratory disorders, particularly asthma and chronic obstructive pulmonary disease (COPD), are major noncommunicable diseases that should be studied over the human lifespan so that prevention strategies can be implemented before these diseases become established. Chronic obstructive respiratory diseases, in fact, appear to have their roots in the early stages of life, even though they may become clinically apparent only later on. An international workshop recently analysed data on asthma and allergies from over 130 birth cohorts, shedding more light on the natural history of these conditions and confirming the importance of gene-environment interactions as well as early-life risk factors [1]. There is also growing evidence of a link between early adverse environmental exposures and chronic noncommunicable diseases (obesity, type 2 diabetes, cardiovascular diseases and neurocognitive disorders), but this topic is covered elsewhere in this series.

We used recent literature to analyse the crucial aspects of the early stages of lung development, going back to prenatal and perinatal events, and we discuss how noxious factors encountered early on may have a lifelong impact on respiratory health (fig. 1). We did not intend to perform a systematic review of the literature with evidence grading. Articles were identified from searches of PubMed using Medical Subject Heading. We did not use any selection or rejection criteria. Review articles are cited.

\section{Lung morphogenesis and regeneration/repair}

Lung morphogenesis begins at 5 weeks of gestation and comprises five different stages, the last of which, alveolarisation, continues postnatally for at least the first 2-4 years of life [2]. Recent studies on lung growth using hyperpolarised helium-3 magnetic resonance imaging (MRI) suggest that alveolarisation may continue throughout childhood and adolescence, and even into adulthood [3].

Perinatal insults can alter both gene expression and epigenetic determinants with potential long-term consequences that might influence the lung's capacity for repair and thus play a part in the pathogenesis of lung disease in adults [4]. Although other distinctive mechanisms, such as those related to inflammation, are involved as well, studies on lung damage have also demonstrated that lung repair processes reiterate many mechanisms and pathways implicated in the lung's original development [5].

A first aspect crucial to both lung development and lung regeneration/repair is the interaction between the endoderm and mesoderm cell types. Extensive epithelial damage with exposure of the basal lamina gives rise to inflammation and cell apoptosis [6]. If the subsequent regeneration process is ineffective, then remodelling occurs with the aberrant tissue features (e.g. fibrosis and emphysema) typical of several chronic respiratory diseases $[6,7]$.

A second aspect involves a number of pathways mediated by growth factors and cytokines common to both lung development and lung repair processes. An important example concerns transforming growth factor beta (TGF)- $\beta$ signalling: appropriate levels of TGF- $\beta$ are crucial to lung development [8] but excessive levels

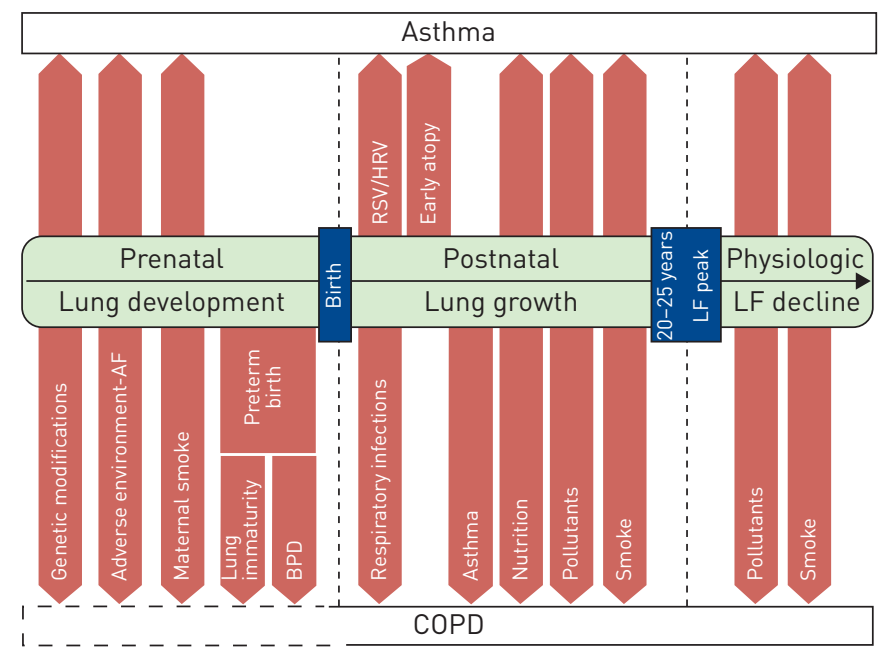

FIGURE 1 Factors involved in asthma and chronic obstructive pulmonary disease (COPD) pathogenesis over the lifespan and their relationship to lung function (LF) trajectory. The green box represents the course and milestones of LF over the lifespan. The red arrows represent the noxae that may contribute to diverting lung health from a physiological to a pathological condition (asthma or COPD). AF: amniotic fluid; BPD: bronchopulmonary dysplasia; RSV: respiratory syncytial virus; HRV: human rhinovirus. 
in the adult lung promote progressive fibrosis $[9,10]$, the hallmark of remodelling. Likewise, the vascular endothelial growth factor (VEGF) has a crucial role in the development of normal lung circulation in the foetus and the newborn [11]. However, VEGF ligands may be involved in the pathogenesis of several lung diseases because the final effect on microvascular endothelial regeneration and repair in response to alveolar hypoxia depends on VEGF ligand balance and relative concentrations [12].

Taken together, these data indicate that lung diseases can be considered in the light of Barker's hypothesis on the "developmental origins of adult disease" [13]. Applied to the lung, this hypothesis points to a connection between impaired lung development and chronic lung disease. This connection relates, on the one hand, to long-term changes in lung structure and metabolism due to noxae encountered early in life, with the potential for generating a maladaptive response to harmful agents in adulthood [8]. However, it relates to the reiteration of developmental mechanisms and pathways in the pathogenesis of lung disease [2].

\section{Early immune maturation and respiratory health}

Neonates have a peculiar immune system that makes them susceptible to severe infections. This is partly because the neonatal immune system is equipped to be tolerant of novel, harmless environmental antigens. An adaptive immune response is essentially lacking because the newborn immune system has no memory, leaving the newborn dependent on innate immune defence mechanisms. It has long been established that infants are born with a T-helper cell (Th) type 2 bias due to a limited capacity to produce Th1 cytokines [14]. Although most cell types are present in normal concentrations in the newborn's blood, they lack the capacity to mount adult-like Th1 instructive signals, and to produce interleukin (IL)-12 $2^{\mathrm{p}^{70}}$ in particular [15]. Immature immune responses in the neonate are the key obstacle to vaccination with polysaccharide vaccines (such as pneumococcal vaccines) at an early age. Antigen-presenting cells in neonates show weaker responses to innate stimuli than do those in adults, except for Toll-like receptor (TLR)-mediated responses to TLR8 agonists [16]. TLR agonists generally promote Th1 development and have been therapeutically developed to prevent and treat allergic diseases, albeit with conflicting results [17]. The effect of innate immune responses on the onset of allergies depends on the timing, dose and site of stimulation [18]. Experimental and human observational studies have shown that the magnitude of mucosal innate immune stimulation determines whether innate responses prevent or enhance the onset of allergic reactions [19, 20]. Preclinical studies suggest that repeated administration of high-dose TLR agonists in the airways prevents allergic airway inflammation. A natural exposure to TLR agonists in early life, as seen in children born on farms, appears to protect against allergic airway disease [21,22], and coincides with an increased expression at birth of innate immunity genes such as TLR2, TLR5, TLR7 and TLR8 [23]. A high exposure to innate immunity-stimulating molecules, such as TLR agonists, is probably needed to prompt this beneficial effect [24]. Being conceived and raised in a farming environment appears to have a beneficial effect that persists at least into later childhood $[25,26]$ and may therefore provide a healthy lifestyle for those at risk of developing allergic asthma. Pharmaceutical agonists of TLR4, TLR7, TLR8 and TLR9 have been developed to treat or prevent allergic disease, and have been tested in clinical studies. In a proof-of-concept study, the TLR9 agonist QbG10 was used with a view to preventing or treating allergic asthma: the condition was controlled in two thirds of the 33 treated adult patients with mild-to-moderate allergic asthma, as opposed to one third of those given a placebo [27]. The further development of these drugs will give us a better understanding of the influence of timing, dose, site of activation and the host's genetic background on the relationship between innate immunity stimulation and the onset of allergic asthma.

New data are also emerging on the relationship between the airway microbiome and the immune system. Neonatal asymptomatic bacterial colonisation (with Moraxella catarrhalis and Haemophilus influenzae) of the respiratory tract has recently been found to be associated with an inflammatory/immune response of the airway mucosa (with increased levels of inflammatory cytokines) and the onset of asthma in childhood [28, 29].

\section{Early environmental factors influencing the development of asthma and COPD}

Factors acting early in life may have profound effects on lifelong respiratory health. These factors may take effect at different times: during intrauterine life (e.g. amniotic fluid composition, exposure to nicotine and maternal vitamin intake), in the perinatal period (e.g. factors relating to premature delivery and the onset of bronchopulmonary dysplasia (BPD)) and postnatally (e.g. exposure to nicotine and environmental chemicals, diet, viral infections, and early allergic sensitisation).

The "exposome" concept has recently been proposed as a new paradigm encompassing the totality of human environmental (nongenetic) exposures from conception onwards, complementing the genome [30]. In the following sections, we discuss recent data on the effects of amniotic fluid composition, exposure to nicotine and environmental chemicals, diet, vitamin intake, allergic sensitisation, and viral infection on lifelong respiratory health. 


\section{First lung exposure: the amniotic fluid}

The fetal airways are continuously exposed to the amniotic fluid. A shortage of fluid (oligohydramnios) due to abnormal urinary tract development or early rupture of membranes (before the 26th week of gestation) gives rise to lung hypoplasia [31]. One of the crucial markers of lung maturity in prematurely born infants is the amniotic fluid concentration of surfactant proteins, particularly SP-B and SP-C, whereas SP-A and SP-D are considered part of the innate immune system, protecting the fetal and infant lung against microorganisms and facilitating the phagocytosis of apoptotic cells. Animal studies have shown that SP-A and SP-D defects may cause allergic airway disease [32]. To date, there has been little research on how amniotic fluid composition at various times during a pregnancy relates to the development of chronic airway disease. Amniotic fluid is rich in proteins and reaches high concentrations of proinflammatory cytokines, including tumour necrosis factor, by the time of delivery [33]. The concentrations of these cytokines in normal amniotic fluid at birth are on the order of nanograms per millilitre, and therefore higher than that in the synovial fluid of patients with septic arthritis or in the cerebrospinal fluid of patients with bacterial meningitis [34]. In very low birth weight infants (and especially in those with sepsis), perinatal inflammation has been associated with the onset of chronic lung disease [35]. In apparent contrast, chorioamnionitis was found to protect against chronic lung disease in a sample of 798 children born preterm, especially in those with no signs of sepsis [36]. Such studies suggest a complex interplay between normal intrauterine inflammation during pregnancy, incomplete lung maturation and the harmful effects of bacterial infections, for instance.

A recent meta-analysis on 147000 European infants showed that gestational age, even beyond 37 weeks, correlated inversely with the risk of asthma at school age [37]. This may be explained by higher concentrations in the amniotic fluid of signals such as proinflammatory mediators that would induce fetal lung maturation [37]. Variations in amniotic fluid composition may also help to explain why preterm birth and caesarean section are risk factors for asthma. In a recent study, lower concentrations of matrix metalloproteinases in the amniotic fluid of mothers delivering by scheduled caesarean section were associated with airway disease in their offspring's childhood [38]. When infants are born by scheduled caesarean section, the amniotic fluid has a particular composition [34] with lower concentrations of inflammatory mediators. This may explain their greater risk of airway disease in the long term [39]. In addition, vaginal delivery may protect against the onset of allergic asthma via the newborn's acquisition of bacteria such as Clostridium difficile at birth [40]. We are convinced that the interaction between fetal airway development and exposure to protein-rich amniotic fluid warrants further study as an essential step to clarifying normal prenatal airway development.

\section{Second-hand smoke exposure}

Maternal smoking during pregnancy is a known risk factor for impaired lung function and respiratory disease in children. A pooled analysis of eight birth cohort studies showed that maternal smoking during pregnancy independently resulted in a 39-65\% increased risk of wheezing and asthma at $4-6$ years of age [41]. Another meta-analysis of 79 cohort studies showed that prenatal maternal smoking caused an increased risk (28-52\%) of wheezing in children, depending on the children's age (OR 1.52 in children aged 5-18 years) [42]. Similarly, a retrospective study on lung function data concerning 20000 children at the age of 6-12 years showed that smoking during pregnancy was independently associated with a lower forced expiratory volume in $1 \mathrm{~s}$ (FEV1) $(-1--6 \%)$ [43]. Similar effects on lung function and the presence of respiratory symptoms at school age have been reported for postnatal exposure to tobacco smoke [44, 45]. In a cohort study, passive smoking during the first year of life increased the risk of respiratory symptoms at 5 years of age in children born moderately preterm, with an adjusted odds ratio of 1.8 [45]. The previously mentioned meta-analysis of 79 prospective studies found an $18-70 \%$ higher incidence of wheezing in children exposed to postnatal maternal smoking (OR 1.70 in children $\leqslant 2$ years of age) [42]. Prospective birth cohort studies following children up to adult age showed a persistence of the harmful effects of prenatal and postnatal tobacco smoke exposure [46-49]. In a birth cohort of 1314 children from Germany, maternal smoking during pregnancy almost doubled the risk of asthma at the age of 20 years [49]. A retrospective study examined lung function in 16832 young adults from the general population, finding that maternal smoking was associated with a small but significant effect on lung function [50].

A possible mechanism underlying the harmful effects of maternal smoking on fetal lung development could be dysregulated cytokine production [51]. Maternal smoking was associated with a greater risk of lower concentrations of IL-4 and interferon- $\gamma$ in cord blood, and with wheezing at 6 years old. Earlier studies by SEKHON and co-workers $[52,53]$ found that, after crossing the placenta, nicotine can interact directly with nicotinic acetylcholine receptors in the lungs of monkeys, thereby altering lung development and resulting in impaired lung function at birth. More recent research has suggested an interaction of in utero and earlylife smoke exposure with asthma susceptibility genes [54]. This finding highlights the fact that there are still 
unresolved questions regarding the mechanisms by which exposure to tobacco smoke impairs lung development and enhances respiratory disease.

Efforts to reduce second-hand smoke (SHS) exposure during and after pregnancy are very important. Various publications have reported the beneficial effects of such efforts on hospitalisation rates and emergency department visits, and on the prevalence of asthma during childhood $[55,56]$. Stopping women from smoking before or during pregnancy remains a challenge, however, as illustrated by the conflicting outcomes of intervention studies [55, 57, 58]. A randomised controlled trial (RCT) comparing nicotine patches with placebo in pregnant smokers showed no significant effects on mothers' smoking rate or reported respiratory symptoms in their offspring at 2 years of age [57]. On the other hand, smoke-free legislation might facilitate a reduction in pregnant women's SHS exposure. A recent meta-analysis of 11 studies on the effect of smoke-free legislation in the USA and Europe showed a 10\% reduction in emergency department visits for asthma [59].

In the field of tobacco control, further investigations are warranted to ascertain the health effects of socalled "third-hand smoke", i.e. toxic residues of tobacco smoke remaining on surfaces and in dust, and still circulating in the air after a cigarette has been extinguished [60].

\section{Exposure to environmental chemicals}

Several environmental agents, such as airborne pollutants and industrial chemicals related to plastic product manufacturing, are recognised risk factors for chronic obstructive airway diseases.

Two main sources of air pollution have been studied in relation to asthma and COPD, i.e. traffic emissions and biomass fuels $[61,62]$. A higher risk of asthma was found among subjects exposed to traffic-related pollutants in utero and during their first year of life [63]. Exposure to high levels of traffic-related pollutants in childhood has been associated with lung growth impairment, which regresses when children move to areas with cleaner air [64]. Indoor biomass burning for cooking and/or heating represents the main source of indoor air pollution in developing countries. An association has been clearly demonstrated between children's exposure to biomass fuels and their morbidity and mortality from respiratory infections, whereas contradictory results have been reported on the association between indoor biomass fuel exposure and the risk of asthma [62].

Regarding industrial chemicals, some studies have implicated exposure to plastics in the onset of childhood respiratory problems, although it is not clear whether specific plastic components act as specific risk factors $[65,66]$. It was recently demonstrated that prenatal and early-life exposure to bisphenol A (BPA), a xenooestrogen used to manufacture plastics (e.g. for toys and drinking vessels), is associated with an increased risk of wheezing and asthma $[67,68]$. The phthalates used in numerous plastic consumer products have also attracted attention and there is converging evidence that exposure to di(2-ethylhexyl)phthalate and benzylbutylphthalate during childhood is associated with the development of allergic disease [69].

\section{Diet}

The influence of eating patterns, dietary content and micronutrient intake on respiratory and allergic disease is an intriguing but rather broad topic to review. We therefore focus on the results of intervention studies. So far, 129 clinical trials on nutrition have been undertaken according to the trial register at www. clinicaltrials.gov (fig. 2).

Prenatally, the diet of pregnant women has been studied as a risk factor for childhood asthma. Most birth cohort studies assessing the effect on childhood asthma of maternal food intake during pregnancy (e.g. the amount of dairy products, wheat, nuts, fish, fruit and vegetables) and dietary patterns (e.g. the Mediterranean diet) found no such association [70-73]. A birth cohort study examining lung function and bronchial responsiveness in children aged 8-9 years also found no association with maternal diet during pregnancy (e.g. whether a healthy, vegetarian or "processed" diet) [74]. On the other hand, poor maternal nutrition during pregnancy has been associated with an increased prevalence of obstructive airway disease in adulthood [75].

Specific micronutrient intake during pregnancy has also been extensively studied. A cohort study measuring neonatal cord blood folate, homocysteine and vitamin $B_{12}$ levels in a sample of 2001 neonates found no association with asthma at 6 years of age [76]. KALLIOMÄKI et al. [77] found that probiotic supplementation during pregnancy was effective in reducing allergic disease (atopic eczema) in children, but two metaanalyses of RCTs assessing the effects of probiotics taken during pregnancy on childhood wheezing, respiratory infections and asthma were unable to confirm any protective effect of probiotics against allergic diseases $[78,79]$. One RCT among pregnant Nepalese women showed that vitamin A, but not $\beta$-carotene, supplementation improved their children's adjusted FEV1 and forced vital capacity (FVC) [80]. As for 


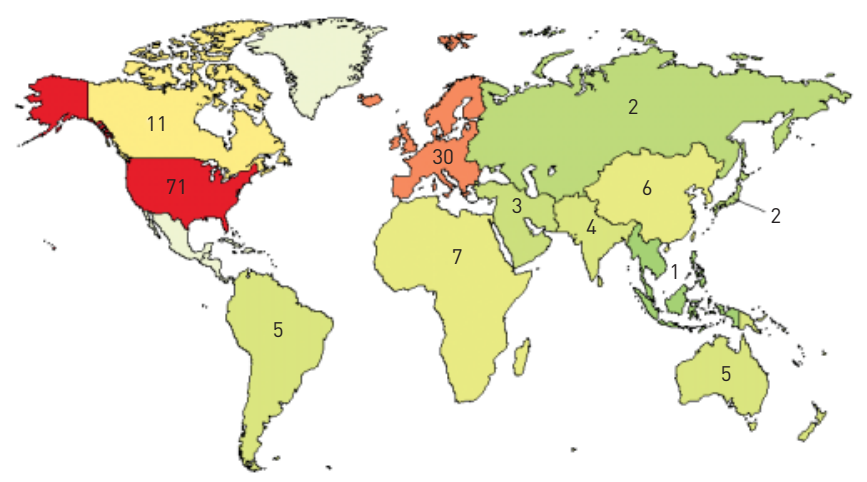

FIGURE 2 Current clinical trials $(\mathrm{n}=129)$ on dietary interventions in children with a respiratory outcome. The number of studies per region is shown. Trials with unknown trial status were excluded. Data from www.clinicaltrials.gov (retrieved July 22, 2014).

vitamin E, an RCT among 643 pregnant women found no effects on their children's respiratory outcome at 2 years of age [81]. Studies on folic acid intake during pregnancy and asthma in children have also generally found no association between the two [82-85]. According to several large birth cohort studies, vitamin D intake or plasma levels during pregnancy are generally not associated with childhood asthma or lung function [86-89], and an RCT examining the effects of vitamin D supplementation during pregnancy $(\mathrm{n}=180)$ found no significant difference in children's wheezing at 3 years of age [90].

Postnatally, breastfeeding is known to protect against various childhood respiratory diseases, but an extensive discussion of this issue is beyond the scope of this review. In addition to breastfeeding, two recent cohort studies showed that greater food diversity during the first year of life reduced the risk of childhood asthma and food allergies [91, 92]. Vitamin D supplementation might promote healthy lung development but evidence is conflicting. A birth cohort study on 436 children found that their vitamin D plasma levels and vitamin D supplementation were not associated with their lung function at 6-7 years of age [86]. However, an RCT among 744 Mongolian school-age children showed that vitamin D supplementation significantly increased their serum levels of 25-hydroxyvitamin D and halved their risk of acute respiratory infections [93]. The relationship between lower serum 25-hydroxyvitamin D levels and a higher risk of respiratory infection was also confirmed by a Canadian study [94]. The need for high-quality, large-scale food intervention studies was highlighted in a recent review of 87 meta-analyses of vitamin D trials that failed to show any clear benefit of vitamin D supplementation for any medical outcomes [95].

A separate mechanism by which infant diet could lead to asthma is rapid weight gain during infancy. A recent meta-analysis of 31 birth cohort studies (147252 children) showed that rapid weight gain during infancy was an independent risk factor for preschool wheezing and school-age asthma [37]. This is consistent with numerous reports of an association between obesity and asthma. Hypotheses on the mechanism behind these associations include genetic predisposition, in utero exposures, immunomodulatory or endocrine pathways, mechanical changes, and lifestyle factors [96].

Taken together, maternal and childhood diet affect normal lung development but a detailed understanding of the connection is still lacking. Future research will provide insight into the interplay between diet, body composition and lung development.

\section{Allergic sensitisation}

Allergic sensitisation in infancy has been seen as a crucial first step in the development of asthma and reduced lung function over time [97, 98]. Synergistic interactions between allergic sensitisation and viral respiratory infections in early life appear to be important in exacerbating the risk [99]. Allergic sensitisation precedes wheezing illness induced by human rhinovirus (HRV) in children who subsequently develop asthma [100]; this typically occurs in children with a genetic predisposition [101]. Trials aimed at preventing the onset of asthma by avoiding contact with allergens have had conflicting results. In a group of 120 non-sensitised, high-risk infants, avoiding house dust mites by using mattress covers proved successful in preventing allergic asthma [102]; at 18 years old, this group still had a lower prevalence of asthma than the control group [103]. In sharp contrast, other trials found that allergen avoidance produced no or even deleterious effects [104-106]. Taken together, these studies fail to support a role for either allergen avoidance or allergen exposure in preventing the inception of allergic airway disease. Nonetheless, a multifaceted approach (mite reduction, breast-feeding and smoking cessation) could have a greater chance 
of being successful $[103,107]$. For food allergens, however, there is evidence to suggest that early exposure prevents allergic sensitisation [108]. Likewise, delaying the first introduction of hen's eggs to children's diets until after the age of 10 months was associated with a threefold higher risk of allergic sensitisation [109].

Allergen avoidance and exposure have also been considered for the secondary prevention of asthma in already-sensitised individuals, with conflicting results [110]. In patients with allergic rhinitis, large observational and small randomised studies have shown that immunotherapy may prevent progression to asthma. Grass- or birch-specific immunotherapy prevented asthma from developing in 50\% of a group of young adults with allergic rhinitis for up to 10 years after treatment [111]. However, large randomised studies are needed to confirm that this form of secondary asthma prevention is safe and effective.

\section{Viral respiratory infections}

Respiratory infections during infancy are associated with the onset of childhood asthma. A birth cohort from Sweden consisting of 42334 children hospitalised for respiratory infections during their first year of life [112] was compared with 211594 control subjects. It was found that experiencing a viral or bacterial respiratory infection at $<12$ months old resulted in a $50 \%$ higher risk of asthma at 5 years of age; this increased risk of asthma persisted up to 16 years of age. Other (mainly retrospective) studies found respiratory infection during childhood to be a risk factor for COPD [50, 113]. Research has been conducted mainly on viral respiratory infections associated with wheezing, such as respiratory syncytial virus (RSV) and HRV, so in the remainder of this section, we focus on the mechanisms and risks of RSV- and HRVrelated chronic respiratory morbidity.

The causative mechanism behind the association between viral respiratory infections and long-term respiratory morbidity has been the subject of much research. It is argued that respiratory pathogens raise an individual's susceptibility to lung impairment and asthma via various immunological pathways. However, it may be that an underlying immunological weakness increases the risk of respiratory infection and asthma [114]. A nonrandomised trial among late-preterm infants showed that preventing RSV by means of virusspecific antibody prophylaxis reduced the risk of recurrent wheezing in childhood by $68-80 \%$ [115]. This effect was seen only in children with no family history of atopy, however, suggesting that atopy and RSV have distinct roles in the pathophysiology of wheezing illness [115]. A RCT among 429 preterm infants found conclusive evidence of a $61 \%$ reduction in the total days of wheezing in the first year of life in infants given RSV prophylaxis as opposed to a placebo; this effect was seen in both atopic and nonatopic children [116]. RSV causes severe disease during infancy. About 1\% of all children require hospitalisation for RSV infection in their first year of life [117]. Cohort studies have shown that up to $50 \%$ of children who experienced a severe RSV infection during infancy were diagnosed with asthma at school age [118-121]. A meta-analysis estimated an overall odds ratio of 3.84 for asthma [122] in children with a history of RSV infection. That study also showed that the relationship between asthma and a history of RSV infection declined with age, confirming previous reports [123]. A recently published birth cohort study conducted among 1246 children followed up to the age of 29 years showed that RSV infection during childhood alone was not associated with any increased adult asthma, but adult smokers with a history of childhood RSV had a 1.7-fold higher risk of asthma than nonsmokers with a history of RSV infection [124]. The mechanism by which RSV causes recurrent wheezing is not entirely clear. An influx of neutrophils to the airways prompted by the RSV infection may plausibly be associated with damage to the airway architecture, resulting in wheezing and shortness of breath when any subsequent viral infection occurs [125, 126].

The nature of the relationship between HRV and the onset of asthma may be quite different. HRV infection usually causes only mild illness [127]. The authors of the Childhood Origins of Asthma (COAST) birth cohort study among 259 children with an atopic background showed that allergic sensitisation preceded HRV wheezing illness, arguing against a causative role for HRV in the inception of asthma [100]. However, $\mathrm{HRV}$-associated wheezing illness has an even stronger relationship with impaired lung function and asthma at school age (6-8 years) than does RSV infection [128, 129]. In COAST, HRV-induced wheezing illness during the first year of life was associated with a 2.9-fold risk of asthma at the age of 6 years [129]. Other community-based studies confirmed a strong association between HRV-associated wheezing illness and the risk of asthma at school age [130].

In short, RSV infection is causally related to subsequent preschool wheezing, but whether or not this effect extends to the onset of asthma or COPD later in life remains to be seen. HRV-associated wheezing illness during infancy is strongly related to asthma at school age but epidemiological studies have yet to demonstrate a causal relationship.

Finally, genetic variances are believed to have a role in virus-mediated asthma pathogenesis: variants of the $17 q 21$ locus are associated with the onset of asthma. In two cohort studies, these variants were also related to early-life infections and HRV-induced wheezing $[101,131]$. A recent study also showed that COPD genes 
are associated with early transient wheezing, pointing to a possible link between COPD and viral respiratory infections during infancy [132].

\section{Long-term consequences of prematurity and BPD}

In this section, we discuss the impact on respiratory health of early-life events related to premature birth and lung immaturity, with or without the associated onset of BPD.

The lung develops in five phases: the embryonic period (up to week 6), the pseudoglandular period (weeks 6-16), the canalicular period (weeks 16-24), the saccular period (weeks 24-40) and the alveolarisation period (which takes place mostly after birth) [133]. Preterm babies born before the 32nd week of gestation have lungs in the saccular stage of development at birth. This means that the alveoli are incompletely developed, the air-blood barrier is still too thick to allow efficient gas exchange and the surfactant system is immature [133]. Premature birth interrupts lung development and its subsequent maturation occurs out of phase, resulting in airways that are more compliant, smaller and with fewer alveolar attachments [134]. Most premature newborns are also exposed to intrauterine inflammation [135], which might further interfere with lung development and have a role in BPD, although this issue is still debated. In addition to prenatal factors, a number of early postnatal noxae, such as hyperoxia and volutrauma, may exacerbate the newborn's lung damage, affecting airway growth, alveolarisation and microvascularisation, and leading to BPD [136].

BPD is a chronic obstructive lung disease that occurs in premature infants, especially in those with respiratory distress requiring ventilatory support and oxygen supplementation. BPD is defined as the need for supplemental oxygen for at least 28 days after birth [137]. Advances in neonatal care have modified the characteristics of BPD, prompting a distinction between "old BPD" (mainly involving subjects born in the pre-surfactant era) and "new BPD" (usually affecting subjects born in the post-surfactant era). From a pathological standpoint, old BPD is characterised mainly by alveolar septal fibrosis and inflammation, and new BPD is characterised by impaired alveolar growth [138, 139].

From a functional standpoint, mid- and long-term follow-up studies conducted in children born prematurely have shown a substantial "tracking" of their lung function. This long-term tracking is a general characteristic of lung function, as demonstrated by the strong correlation found between lung function at 2 months and at 11, 16 and 22 years of age in an unselected birth cohort [140]. This suggests that poor airway function shortly after birth is an inescapable risk factor for airflow obstruction in young adults [140].

Although some authors have reported a degree of improvement in airway obstruction as BPD subjects grow older [141, 142], most longitudinal studies have demonstrated a persistently reduced lung function throughout childhood, adolescence and early adulthood [138, 143-145]. Significant functional impairment has also been seen in preterm-born, non-BPD subjects (although less pronounced than in BPD subjects), confirming the important functional impact of prematurity per se even beyond the first year of life [143].

Their persistent functional deficit prevents BPD subjects from achieving their full respiratory potential, but the lungs of the prematurely born seem to be more vulnerable too. A steeper than normal decline in FEV1/ FVC has been described in adolescents born preterm, suggesting that their respiratory health deteriorates sooner than it does in their term-born peers [146]. A progressive functional deterioration has also been reported in BPD subjects who experienced a more severe airflow obstruction in infancy, confirming the important long-term effect of perinatal lung injuries [147].

Interestingly, significant impairments of airway function have been reported not only in "old BPD" patients, but also in BPD children born in the post-surfactant era [148-151]. This finding underscores the detrimental effect of lung immaturity on respiratory health over the years, even when surfactants and antenatal steroids were used and ventilatory support was less aggressive. Some recent ${ }^{3} \mathrm{He}-\mathrm{MRI}$ studies nonetheless suggest that alveolarisation may "catch up" in preterm subjects during their first decade of life despite a persistent airway obstruction [152].

From a clinical standpoint, preterm-born subjects (particularly those with BPD) have a higher burden of respiratory symptoms than do healthy control subjects $[138,153,154]$. Although this difference tends to fade with age, data collected in young adults still indicate a greater recurrence of respiratory symptoms in the preterm-born than in the term-born individuals [142]. The higher respiratory morbidity associated with premature birth may be partly due to reduced airway calibre, but it may also be a consequence of neonatal exposure to hyperoxia, which can exacerbate inflammatory responses and lead to changes in key immunoregulatory pathways [150]. It is noteworthy that even late-preterm children (born between the 34th and 36th week of gestation) have a significantly higher than normal respiratory morbidity [45, 155-158], which has been related to lung vulnerability due to immaturity, perinatal factors and a greater susceptibility to RSV infection [158]. 
It is worth adding that, although children with chronic lung disease after premature birth and children with asthma share some clinical and physiological features (recurrent wheezing and flow limitation on spirometry), there are different underlying mechanisms. In our opinion, the term asthma should be avoided when referring to ex-preterm and BPD children to avoid the risk of them being given ineffective or even unsafe chronic treatments [159].

Finally, it is worth remembering that BPD is frequently associated with other, nonrespiratory conditions relating to preterm birth, such as growth retardation, pulmonary hypertension, neurodevelopmental delay, hearing defects and retinopathy of prematurity [154].

\section{Early origin of COPD}

COPD is an umbrella term for a spectrum of diseases characterised by an airflow limitation that is not fully reversible. It is set to become the third most important cause of death globally by 2020 [160]. A growing number of studies suggest that not only cigarette smoke but also several other factors are involved in the pathogenesis of COPD. Alongside those taking effect in adulthood, the role of perinatal and early-infancy factors, including prematurity and BPD, has recently been stressed [161, 162], and an association has been suggested between low birth weight and both airflow limitation in adulthood $[163,164]$ and death due to COPD [165]. Likewise, it has been demonstrated that some childhood disadvantages (parental asthma, childhood asthma, childhood respiratory infections and maternal smoking) have much the same impact on adult lung function and the risk of COPD as heavy smoking [50], suggesting that COPD can be seen as a disease of childhood that becomes manifest in adults $[124,166]$.

The hypothesis of an early origin of chronic respiratory diseases supports the theory that noxae acting during periods crucial to lung development may give rise to permanent structural or functional changes in the lung, with potential lifelong consequences [136, 167]. In addition, the modification of genetic pathways involved in lung development and changes to immunoregulatory pathways in response to detrimental conditions may lead to long-term altered lung homeostasis. This might prompt abnormal responses to harmful agents (e.g. cigarette smoke or pollutants), resulting in a faster degeneration of respiratory function $[168,169]$.

Alongside such an accelerated decline in lung function, a recognised risk factor for COPD is failure to reach the expected peak lung function during early adulthood $[138,160]$, as often happens after preterm birth. In fact, prematurely born subjects (with or without BPD) may not reach their maximum potential lung function during early adulthood because their lung development is impaired due to the combined effects of prematurity and noxious agents acting early in life (e.g. hyperoxia) or later on (e.g. smoking). This means that the physiological age-related decline in lung function may predispose these subjects to a COPD-like phenotype, whereas there is no such significant respiratory impairment in healthy individuals thanks to their available reserves [136]. It is noteworthy that a low FEV1 in adulthood is associated not only with poor respiratory health but also with higher rates of cardiovascular diseases and overall mortality [170].

The hypothesis of an early origin of a COPD-like phenotype related to prematurity and BPD is intriguing but further studies are needed to investigate the biochemical-metabolic processes and pathological changes that lead from BPD to COPD. Pathological data are only available for the early phases of BPD; very little is known about the pathological processes and structural changes occurring in the lungs of BPD and preterm subjects beyond infancy [171].

The likely influence of early-life events on the development of chronic respiratory diseases in adulthood strongly suggests that paediatric and adult respiratory medicine should not be considered separate disciplines, and that adult physicians should be aware of the possible impact of early-life events on an individual's lifelong respiratory health. Interventions to contain negative early-life factors may thus have a significant effect on adult respiratory health and the risk of COPD. Unfortunately, a survey by the British Thoracic Society demonstrated that respiratory physicians rarely ask their adult patients about early-life events [172].

\section{Searching for early biomarkers in chronic respiratory diseases}

Chronic respiratory diseases such as asthma or COPD are extremely complex syndromes owing to the large number of cell types and molecular pathways that contribute to their pathogenesis and interact in complex networks [173-175]. Two further aspects add complexity to the picture: 1) there is a partial overlap in the characteristics of the different chronic respiratory diseases; and 2) their onset in adulthood may be the result of harmful early-life events that have made the lungs more vulnerable for the rest of the subject's life. Although analysing single biomarkers and molecular pathways provides useful information, the great complexity of these conditions demands their study using a more global strategy as well, or what is called a systems biology approach $[173,176]$. Systems biology is defined as the quantitative analysis of the dynamic 
interactions between different components of a biological system based on a combination of mathematical modelling and experimental biology [177]. Systems biology is considered a key factor in the development of personalised medicine and the "-omic" technologies (genomics, proteomics and metabolomics) have the potential to shift the focus of medicine from the traditional symptom-oriented diagnosis and treatment of diseases (reactive medicine) towards the "P4" medicine, which concentrates on preserving health through the prevention and early diagnosis of disease [178].

The "-omic" technologies are systems biology platforms that are not guided by any a priori assumptions. They are used to look into which components are associated with a given pathological condition with a view to shedding light on single phenotypes and new, hitherto unsuspected pathogenic pathways, resulting in a hypothesis-generating approach [179]. Among the "-omics", metabolomics is considered the one that comes closest to phenotype expression, enabling the study of overall metabolic profiles resulting from the joint contribution of genetic information and environmental factors unrelated to the genome [180]. The metabolomic approach has been used successfully to characterise patients who already have asthma [181, 182] or COPD [183]. The next challenge is to apply this novel method very early in life, even before birth, with a view to identifying individuals likely to develop a given chronic respiratory condition. In fact, one of the most promising applications of the metabolomic approach is the early identification of metabolite patterns associated with the subsequent onset of a pathological condition. The potential of such an approach has been demonstrated; for example, in type 1 diabetes, genetically predisposed subjects have a metabolomic profile capable of predicting the onset of the disease before any other immunological or clinical signs become apparent [184]. Similarly, metabolomic analysis of the amniotic fluid has been used to identify subjects at risk of preterm delivery $[185,186]$. In the field of respiratory medicine, the feasibility of identifying metabolomic profiles predictive of chronic lung diseases such as asthma or COPD would be particularly appealing, given the assumption of their early origin. Characterising such early predictive metabolomic patterns would have a profound impact on the management of these conditions, potentially enabling the implementation of effective preventive strategies and/or targeted early therapeutic approaches [187, 188].

\section{Conclusions}

In this narrative review, we discussed evidence from the recent literature highlighting the need to take a lifespan approach to studying chronic respiratory diseases. A growing body of data supports the conviction that early-life factors play a fundamental part in the later onset of diseases such as asthma and COPD, and the early postnatal period appears to offer a specific window of opportunity for intervention. A better awareness of the close links between early-life lung events and adult respiratory diseases should prompt a greater effort to improve early prevention strategies with a view to ensuring a beneficial impact on both short- and long-term respiratory health.

We have attempted to discuss the most important factors with an impact on long-term respiratory health. Some of them are modifiable, such as SHS exposure, and every effort to prevent maternal smoking during and after pregnancy should be strongly supported. Other factors might be modifiable, such as those related to mothers' and children's diets, but further trials are needed before recommendations can be made relating to specific dietary measures. Finally, there are early factors with a clear negative impact on later respiratory health, such as premature birth, viral respiratory infections and allergic sensitisation, for which further studies are needed to identify effective prevention strategies.

The pathways and mechanisms involved in the relationship between early-life events and chronic respiratory diseases in adulthood warrant further investigation, including novel approaches, such as the high-throughput "-omic" technologies. A better understanding of how these diseases evolve over the lifespan will improve our ability to treat and prevent them. More investment in high-quality paediatric respiratory research in early life is a crucial part of the effort to ensure healthy respiratory ageing.

\section{References}

1 Bousquet J, Gern JE, Martinez FD, et al. Birth cohorts in asthma and allergic diseases: Report of a NIAID/NHLBI/ MeDALL joint workshop. J Allergy Clin Immunol 2014; 133: 1535-1546.

2 Bhattacharya S, Mariani TJ. Systems biology approaches to identify developmental bases for lung diseases. Pediatr Res 2013; 73: 514-522.

Butler JP, Loring SH, Patz S, et al. Evidence for adult lung growth in humans. N Engl J Med 2012; 367: 244-247.

4 Joss-Moore LA, Albertine KH, Lane RH. Epigenetics and the developmental origins of lung disease. Mol Genet Metab 2011; 104: 61-66.

5 Shi W, Xu J, Warburton D. Development, repair and fibrosis: what is common and why it matters. Respirology 2009; 14: 656-665.

6 Holgate ST. The sentinel role of the airway epithelium in asthma pathogenesis. Immunol Rev 2011; 242: $205-219$.

7 Beers MF, Morrisey EE. The three R's of lung health and disease: repair, remodeling, and regeneration. J Clin Invest 2011; 121: 2065-2073. 
Shi W, Chen F, Cardoso WV. Mechanisms of lung development: contribution to adult lung disease and relevance to chronic obstructive pulmonary disease. Proc Am Thorac Soc 2009; 6: 558-563.

9 Sime PJ, Xing Z, Graham FL, et al. Adenovector-mediated gene transfer of active transforming growth factor-beta1 induces prolonged severe fibrosis in rat lung. J Clin Invest 1997; 100: 768-776.

10 Morty RE, Königshoff M, Eickelberg O. Transforming growth factor-beta signaling across ages: from distorted lung development to chronic obstructive pulmonary disease. Proc Am Thorac Soc 2009; 6: 607-613.

11 Abman SH. Impaired vascular endothelial growth factor signaling in the pathogenesis of neonatal pulmonary vascular disease. Adv Exp Med Biol 2010; 661: 323-335.

12 Sands M, Howell K, Costello CM, et al. Placenta growth factor and vascular endothelial growth factor B expression in the hypoxic lung. Respir Res 2011; 12: s17.

13 Barker DJ, Osmond C. Infant mortality, childhood nutrition, and ischaemic heart disease in England and Wales. Lancet 1986; 1: 1077-1081.

14 Zaghouani H, Hoeman CM, Adkins B. Neonatal immunity: faulty T-helpers and the shortcomings of dendritic cells. Trends Immunol 2009; 30: 585-591.

15 Kollmann TR, Levy O, Montgomery RR, et al. Innate immune function by Toll-like receptors: distinct responses in newborns and the elderly. Immunity 2012; 37: 771-783.

16 Levy O, Suter EE, Miller RL, et al. Unique efficacy of Toll-like receptor 8 agonists in activating human neonatal antigen-presenting cells. Blood 2006; 108: 1284-1290.

17 Belderbos M, Levy O, Bont L. Neonatal innate immunity in allergy development. Curr Opin Pediatr 2009; 21: 762-769.

18 Schröder NWJ, Crother TR, Naiki Y, et al. Innate immune responses during respiratory tract infection with a bacterial pathogen induce allergic airway sensitization. J Allergy Clin Immunol 2008; 122: 595-602.

19 Jeon SG, Oh SY, Park $\mathrm{HK}$, et al. $\mathrm{T}_{\mathrm{H}} 2$ and $\mathrm{T}_{\mathrm{H}} 1$ lung inflammation induced by airway allergen sensitization with low and high doses of double-stranded RNA. J Allergy Clin Immunol 2007; 120: 803-812.

20 Kim YK, Oh SY, Jeon SG, et al. Airway exposure levels of lipopolysaccharide determine type 1 versus type 2 experimental asthma. J Immunol 2007; 178: 5375-5382.

21 Schaub B, Liu J, Höppler S, et al. Maternal farm exposure modulates neonatal immune mechanisms through regulatory T cells. J Allergy Clin Immunol 2009; 123: 774-782.

22 Lluis A, Ballenberger N, Illi S, et al. Regulation of $\mathrm{T}_{\mathrm{H}} 17$ markers early in life through maternal farm exposure. J Allergy Clin Immunol 2014; 133: 864-871.

23 Loss G, Bitter S, Wohlgensinger J, et al. Prenatal and early-life exposures alter expression of innate immunity genes: the PASTURE cohort study. J Allergy Clin Immunol 2012; 130: 523-530.

24 Rabinovitch N, Liu AH, Zhang L, et al. Importance of the personal endotoxin cloud in school-age children with asthma. J Allergy Clin Immunol 2005; 116: 1053-1057.

25 Sozańska B, Pearce N, Dudek K, et al. Consumption of unpasteurized milk and its effects on atopy and asthma in children and adult inhabitants in rural Poland. Allergy 2013; 68: 644-650.

26 Varraso R, Oryszczyn MP, Mathieu N, et al. Farming in childhood, diet in adulthood and asthma history. Eur Respir J 2012; 39: 67-75.

27 Beeh KM, Kanniess F, Wagner F, et al. The novel TLR-9 agonist QbG10 shows clinical efficacy in persistent allergic asthma. J Allergy Clin Immunol 2013; 131: 866-874.

28 Bisgaard H, Hermansen MN, Buchvald F, et al. Childhood asthma after bacterial colonization of the airway in neonates. N Engl J Med 2007; 357: 1487-1495.

29 Følsgaard NV, Schjørring S, Chawes BL, et al. Pathogenic bacteria colonizing the airways in asymptomatic neonates stimulates topical inflammatory mediator release. Am J Respir Crit Care Med 2013; 187: 589-595.

30 Vrijheid M. The exposome: a new paradigm to study the impact of environment on health. Thorax 2014; 69: 876-878.

31 Nimrod C, Nicholson S, Davies D, et al. Pulmonary hypoplasia testing in clinical obstetrics. Am J Obstet Gynecol 1988; 158: 277-280.

32 Madan T, Reid KBM, Singh M, et al. Susceptibility of mice genetically deficient in the surfactant protein (SP)-A or SP-D gene to pulmonary hypersensitivity induced by antigens and allergens of Aspergillus fumigatus. J Immunol 2005; 174: 6943-6954.

33 Romero R, Espinoza J, Gonçalves LF, et al. The role of inflammation and infection in preterm birth. Semin Reprod Med 2007; 25: 21-39.

34 Houben ML, Nikkels PGJ, van Bleek GM, et al. The association between intrauterine inflammation and spontaneous vaginal delivery at term: a cross-sectional study. PLoS One 2009; 4: e6572.

35 Lee J, Oh KJ, Yang HJ, et al. The importance of intra-amniotic inflammation in the subsequent development of atypical chronic lung disease. J Matern Fetal Neonatal Med 2009; 22: 917-923.

36 Lahra MM, Beeby PJ, Jeffery HE. Intrauterine inflammation, neonatal sepsis, and chronic lung disease: a 13-year hospital cohort study. Pediatrics 2009; 123: 1314-1319.

37 Sonnenschein-van der Voort AMM, Arends LR, de Jongste JC, et al. Preterm birth, infant weight gain, and childhood asthma risk: A meta-analysis of 147,000 European children. J Allergy Clin Immunol 2014; 133: 1317-1329.

38 Turner SW, Carter J, Danielian P, et al. Protease concentration in amniotic fluid at term and early childhood respiratory symptoms. J Matern Fetal Neonatal Med 2014; 27: 416-420.

39 Cho CE, Norman M. Cesarean section and development of the immune system in the offspring. Am J Obstet Gynecol 2013; 208: 249-54.

40 Van Nimwegen FA, Penders J, Stobberingh EE, et al. Mode and place of delivery, gastrointestinal microbiota, and their influence on asthma and atopy. J Allergy Clin Immunol 2011; 128: 948-955.

41 Neuman A, Hohmann C, Orsini N, et al. Maternal smoking in pregnancy and asthma in preschool children: a pooled analysis of eight birth cohorts. Am J Respir Crit Care Med 2012; 186: 1037-1043.

42 Burke H, Leonardi-Bee J, Hashim A, et al. Prenatal and passive smoke exposure and incidence of asthma and wheeze: systematic review and meta-analysis. Pediatrics 2012; 129: 735-744.

43 Moshammer H, Hoek G, Luttmann-Gibson H, et al. Parental smoking and lung function in children: an international study. Am J Respir Crit Care Med 2006; 173: 1255-1263.

44 Cohen RT, Strunk RC, Field JJ, et al. Environmental tobacco smoke and airway obstruction in children with sickle cell anemia. Chest 2013; 144: 1323-1329. 
45 Vrijlandt EJ, Kerstjens JM, Duiverman EJ, et al. Moderately preterm children have more respiratory problems during their first 5 years of life than children born full term. Am J Respir Crit Care Med 2013; 187: 1234-1240.

46 Hayatbakhsh MR, Sadasivam S, Mamun AA, et al. Maternal smoking during and after pregnancy and lung function in early adulthood: a prospective study. Thorax 2009; 64: 810-814.

47 Hollams EM, de Klerk NH, Holt PG, et al. Persistent effects of maternal smoking during pregnancy on lung function and asthma in adolescents. Am J Respir Crit Care Med 2014; 189: 401-407.

48 Guerra S, Stern DA, Zhou M, et al. Combined effects of parental and active smoking on early lung function deficits: a prospective study from birth to age 26 years. Thorax 2013; 68: 1021-1028.

49 Grabenhenrich LB, Gough H, Reich A, et al. Early-life determinants of asthma from birth to age 20 years: A German birth cohort study. J Allergy Clin Immunol 2014; 133: 979-988.e3.

50 Svanes C, Sunyer J, Plana E, et al. Early life origins of chronic obstructive pulmonary disease. Thorax 2010; 65: 14-20.

51 Macaubas C, de Klerk NH, Holt BJ, et al. Association between antenatal cytokine production and the development of atopy and asthma at age 6 years. Lancet 2003; 362: 1192-1197.

52 Sekhon HS, Keller JA, Benowitz NL, et al. Prenatal nicotine exposure alters pulmonary function in newborn rhesus monkeys. Am J Respir Crit Care Med 2001; 164: 989-94.

53 Sekhon HS, Jia Y, Raab R, et al. Prenatal nicotine increases pulmonary $\alpha 7$ nicotinic receptor expression and alters fetal lung development in monkeys. J Clin Invest 1999; 103: 637-647.

54 Scholtens S, Postma DS, Moffatt MF, et al. Novel childhood asthma genes interact with in utero and early-life tobacco smoke exposure. J Allergy Clin Immunol 2014; 133: 885-888.

55 Chan-Yeung M, Ferguson A, Watson W, et al. The Canadian Childhood Asthma Primary Prevention Study: outcomes at 7 years of age. J Allergy Clin Immunol 2005; 116: 49-55.

56 Gerald LB, Gerald JK, Gibson L, et al. Changes in environmental tobacco smoke exposure and asthma morbidity among urban school children. Chest 2009; 135: 911-916.

57 Cooper S, Taggar J, Lewis S, et al. 2-year infant and maternal outcomes investigating nicotine-replacement therapy for smoking cessation in pregnancy from the SNAP trial: a randomised controlled trial. Lancet 2013; 382: S7.

58 Maas T, Dompeling E, Muris JW, et al. Prevention of asthma in genetically susceptible children: a multifaceted intervention trial focussed on feasibility in general practice. Pediatr Allergy Immunol 2011; 22: 794-802.

59 Been JV, Nurmatov UB, Cox B, et al. Effect of smoke-free legislation on perinatal and child health: a systematic review and meta-analysis. Lancet 2014; 383: 1549-1560.

60 Matt GE, Quintana PJE, Destaillats H, et al. Thirdhand tobacco smoke: emerging evidence and arguments for a multidisciplinary research agenda. Environ Health Perspect 2011; 119: 1218-1226.

61 Health Effects Institute. Traffic-related air pollution: a critical review of the literature on emissions, exposure, and health effects. http://pubs.healtheffects.org/view.php?id=334 Date last updated: February 22, 2011.

62 Laumbach RJ, Kipen HM. Respiratory health effects of air pollution: update on biomass smoke and traffic pollution. J Allergy Clin Immunol 2012; 129: 3-11.

63 Clark NA, Demers PA, Karr CJ, et al. Effect of early life exposure to air pollution on development of childhood asthma. Environ Health Perspect 2010; 118: 284-290.

64 Eisner MD, Anthonisen N, Coultas D, et al. An official American Thoracic Society public policy statement: novel risk factors and the global burden of chronic obstructive pulmonary disease. Am J Respir Crit Care Med 2010; 182: 693-718.

65 Jaakkola JJ, Oie L, Nafstad P, et al. Interior surface materials in the home and the development of bronchial obstruction in young children in Oslo, Norway. Am J Public Health 1999; 89: 188-192.

66 Jaakkola JJ, Verkasalo PK, Jaakkola N. Plastic wall materials in the home and respiratory health in young children. Am J Public Health 2000; 90: 797-799.

67 Donohue K, Miller R, Perzanowski M, et al. Prenatal and postnatal bisphenol A exposure and asthma development among innercity children. J Allergy Clin Immunol 2013; 131: 736-742.

68 Spanier AJ, Kahn RS, Kunselman AR, et al. Prenatal exposure to bisphenol A and child wheeze from birth to three years. Environ Health Perspect 2012; 120: 916-920.

69 Braun JM, Sathyanarayana S., Hauser R. Phthalate exposure and children's health. Curr Opin Pediatr 2013; 25 : 247-254.

70 Bunyavanich S, Rifas-Shiman SL, Platts-Mills TA, et al. Peanut, milk, and wheat intake during pregnancy is associated with reduced allergy and asthma in children. J Allergy Clin Immunol 2014; 133: 1373-1382.

71 Erkkola M, Nwaru BI, Kaila M, et al. Risk of asthma and allergic outcomes in the offspring in relation to maternal food consumption during pregnancy: a Finnish birth cohort study. Pediatr Allergy Immunol 2012; 23: 186-94.

72 Willers SM, Wijga AH, Brunekreef B, et al. Maternal food consumption during pregnancy and the longitudinal development of childhood asthma. Am J Respir Crit Care Med 2008; 178: 124-131.

73 Lange NE, Rifas-Shiman SL, Camargo CA, et al. Maternal dietary pattern during pregnancy is not associated with recurrent wheeze in children. J Allergy Clin Immunol 2010; 126: 250-255.

74 Shaheen SO, Northstone K, Newson RB, et al. Dietary patterns in pregnancy and respiratory and atopic outcomes in childhood. Thorax 2009; 64: 411-417.

75 Lopuhaä CE, Roseboom TJ, Osmond C, et al. Atopy, lung function, and obstructive airways disease after prenatal exposure to famine. Thorax 2000; 55: 555-561.

76 Van der Valk RJP, Kiefte-de Jong JC, Sonnenschein-van der Voort AMM, et al. Neonatal folate, homocysteine, vitamin B12 levels and methylenetetrahydrofolate reductase variants in childhood asthma and eczema. Allergy 2013; 68: 788-795.

77 Kalliomäki M, Salminen S, Arvilommi H, et al. Probiotics in primary prevention of atopic disease: a randomised placebo-controlled trial. Lancet 2001; 357: 1076-1079.

78 Azad MB, Coneys JG, Kozyrskyj AL, et al. Probiotic supplementation during pregnancy or infancy for the prevention of asthma and wheeze: systematic review and meta-analysis. BMJ 2013; 347: f6471.

79 Elazab N, Mendy A, Gasana J, et al. Probiotic administration in early life, atopy, and asthma: a meta-analysis of clinical trials. Pediatrics 2013; 132: e666-e676.

80 Checkley W, West KP, Wise RA, et al. Maternal vitamin A supplementation and lung function in offspring. $N$ Engl $\mathrm{J}$ Med 2010; 362: 1784-1794. 
81 Greenough A, Shaheen SO, Shennan A, et al. Respiratory outcomes in early childhood following antenatal vitamin C and E supplementation. Thorax 2010; 65: 998-1003.

82 Crider KS, Cordero AM, Qi YP, et al. Prenatal folic acid and risk of asthma in children: a systematic review and meta-analysis. Am J Clin Nutr 2013; 98: 1272-1281.

83 Blatter J, Han YY, Forno E, et al. Folate and asthma. Am J Respir Crit Care Med 2013; 188: 12-17.

84 Brown SB, Reeves KW, Bertone-Johnson ER. Maternal folate exposure in pregnancy and childhood asthma and allergy: a systematic review. Nutr Rev 2014; 72: 55-64.

85 Bekkers MBM, Elstgeest LEM, Scholtens S, et al. Maternal use of folic acid supplements during pregnancy, and childhood respiratory health and atopy. Eur Respir J 2012; 39: 1468-1474.

86 Cremers E, Thijs C, Penders J, et al. Maternal and child's vitamin D supplement use and vitamin D level in relation to childhood lung function: the KOALA Birth Cohort Study. Thorax 2011; 66: 474-480.

87 Wills AK, Shaheen SO, Granell R, et al. Maternal 25-hydroxyvitamin D and its association with childhood atopic outcomes and lung function. Clin Exp Allergy 2013; 43: 1180-1188.

88 Camargo CAJ, Ingham T, Wickens K, et al. Cord-blood 25-hydroxyvitamin D levels and risk of respiratory infection, wheezing, and asthma. Pediatrics 2011; 127: e180-e187.

89 Zosky GR, Hart PH, Whitehouse AJ, et al. Vitamin D deficiency at 16-20 weeks gestation is associated with impaired lung function and asthma at 6 years of age. Ann Am Thorac Soc 2014; 11: 571-577.

90 Goldring ST, Griffiths CJ, Martineau AR, et al. Prenatal vitamin D supplementation and child respiratory health: a randomised controlled trial. PLoS One 2013; 8: e66627.

91 Nwaru BI, Takkinen HM, Kaila M, et al. Food diversity in infancy and the risk of childhood asthma and allergies. J Allergy Clin Immunol 2014; 133: 1084-1091.

92 Roduit C, Frei R, Depner M, et al. PASTURE study group. Increased food diversity in the first year of life is inversely associated with allergic diseases. J Allergy Clin Immunol 2014; 133: 1056-1064.

93 Camargo CA, Ganmaa D, Frazier AL, et al. Randomized trial of vitamin D supplementation and risk of acute respiratory infection in Mongolia. Pediatrics 2012; 130: e561-e567.

94 Science M, Maguire JL, Russell ML, et al. Low serum 25-hydroxyvitamin D level and risk of upper respiratory tract infection in children and adolescents. Clin Infect Dis 2013; 57: 392-397.

95 Theodoratou E, Tzoulaki I, Zgaga L, et al. Vitamin D and multiple health outcomes: umbrella review of systematic reviews and meta-analyses of observational studies and randomised trials. BMJ 2014; 348: g2035.

96 Ali Z, Ulrik CS. Obesity and asthma: a coincidence or a causal relationship? A systematic review. Respir Med 2013; 107: 1287-1300.

97 Illi S, von Mutius E, Lau S, et al. Perennial allergen sensitisation early in life and chronic asthma in children: a birth cohort study. Lancet 2006; 368: 763-770.

98 Simpson A, Tan VY, Winn J, et al. Beyond atopy: multiple patterns of sensitization in relation to asthma in a birth cohort study. Am J Respir Crit Care Med 2010; 181: 1200-1206.

99 Sly PD, Boner AL, Björksten B, et al. Early identification of atopy in the prediction of persistent asthma in children. Lancet 2008; 372: 1100-1106.

100 Jackson DJ, Evans MD, Gangnon RE, et al. Evidence for a causal relationship between allergic sensitization and rhinovirus wheezing in early life. Am J Respir Crit Care Med 2012; 185: 281-285.

101 Caliskan M, Bochkov YA, Kreiner-Moller E, et al. Rhinovirus wheezing illness and genetic risk of childhood-onset asthma. N Engl J Med 2013; 368: 1398-1407.

102 Arshad SH, Bateman B, Sadeghnejad A, et al. Prevention of allergic disease during childhood by allergen avoidance: the Isle of Wight prevention study. J Allergy Clin Immunol 2007; 119: 307-13.

103 Scott M, Roberts G, Kurukulaaratchy RJ, et al. Multifaceted allergen avoidance during infancy reduces asthma during childhood with the effect persisting until age 18 years. Thorax 2012; 67: 1046-1051.

104 Woodcock A, Lowe LA, Murray CS, et al. Manchester Asthma and Allergy Study Group. Early life environmental control: effect on symptoms, sensitization, and lung function at age 3 years. Am J Respir Crit Care Med 2004; 170 : 433-439.

105 Koopman LP, van Strien RT, Kerkhof M, et al. Placebo-controlled trial of house dust mite-impermeable mattress covers: effect on symptoms in early childhood. Am J Respir Crit Care Med 2002; 166: 307-313.

106 Simpson A, Custovic A. Prevention of allergic sensitization by environmental control. Curr Allergy Asthma Rep 2009; 9: 363-369.

107 van Schayck OC, Maas T, Kaper J, et al. Is there any role for allergen avoidance in the primary prevention of childhood asthma? J Allergy Clin Immunol 2007; 119: 1323-1328.

108 Katz Y, Rajuan N, Goldberg MR, et al. Early exposure to cow's milk protein is protective against IgE-mediated cow's milk protein allergy. J Allergy Clin Immunol 2010; 126: 77-82.

109 Koplin JJ, Osborne NJ, Wake M, et al. Can early introduction of egg prevent egg allergy in infants? A populationbased study. J Allergy Clin Immunol 2010; 126: 807-813.

110 Gøtzsche PC, Johansen HK. House dust mite control measures for asthma: systematic review. Allergy 2008; 63: 646-659.

111 Mölle RC, Dreborg S, Ferdousi HA, et al. Pollen immunotherapy reduces the development of asthma in children with seasonal rhinoconjunctivitis (the PAT-study). J Allergy Clin Immunol 2002; 109: 251-256.

112 Montgomery S, Bahmanyar S, Brus O, et al. Respiratory infections in preterm infants and subsequent asthma: a cohort study. BMJ Open 2013; 3: e004034.

113 De Marco R, Accordini S, Marcon A, et al. Risk factors for chronic obstructive pulmonary disease in a European cohort of young adults. Am J Respir Crit Care Med 2011; 183: 891-897.

114 Holt PG, Strickland DH, Hales BJ, et al. Defective respiratory tract immune surveillance in asthma: a primary causal factor in disease onset and progression. Chest 2014; 145: 370-378.

115 Simões EAF, Carbonell-Estrany X, Rieger CHL, et al. The effect of respiratory syncytial virus on subsequent recurrent wheezing in atopic and nonatopic children. J Allergy Clin Immunol 2010; 126: 256-262.

116 Blanken MO, Rovers MM, Molenaar JM, et al. Respiratory syncytial virus and recurrent wheeze in healthy preterm infants. N Engl J Med 2013; 368: 1791-1799.

117 Hall CB, Weinberg GA, Iwane MK, et al. The burden of respiratory syncytial virus infection in young children. N Engl J Med 2009; 360: 588-598. 
118 Bacharier LB, Cohen R, Schweiger T, et al. Determinants of asthma after severe respiratory syncytial virus bronchiolitis. J Allergy Clin Immunol 2012; 130: 91-100.

119 Cassimos DC, Tsalkidis A, Tripsianis GA, et al. Asthma, lung function and sensitization in school children with a history of bronchiolitis. Pediatr Int 2008; 50: 51-56.

120 Koponen P, Helminen M, Paassilta M, et al. Preschool asthma after bronchiolitis in infancy. Eur Respir J 2012; 39: $76-80$.

121 Sigurs N, Gustafsson PM, Bjarnason R, et al. Severe respiratory syncytial virus bronchiolitis in infancy and asthma and allergy at age 13. Am J Respir Crit Care Med 2005; 171: 137-141.

122 Regnier SA, Huels J. Association between respiratory syncytial virus hospitalizations in infants and respiratory sequelae: systematic review and meta-analysis. Pediatr Infect Dis J 2013; 32: 820-826.

123 Stein RT, Sherrill D, Morgan WJ, et al. Respiratory syncytial virus in early life and risk of wheeze and allergy by age 13 years. Lancet 1999; 354: 541-545.

124 Voraphani N, Stern DA, Wright AL, et al. Risk of current asthma among adult smokers with respiratory syncytial virus illnesses in early life. Am J Respir Crit Care Med 2014; 190: 392-398.

125 Jones A, Qui JM, Bataki E, et al. Neutrophil survival is prolonged in the airways of healthy infants and infants with RSV bronchiolitis. Eur Respir J 2002; 20: 651-657.

126 McNamara PS, Flanagan BF, Baldwin LM, et al. Interleukin 9 production in the lungs of infants with severe respiratory syncytial virus bronchiolitis. Lancet 2004; 363: 1031-1037.

127 Lemanske Jr RF, Jackson DJ, Gangnon RE, et al. Rhinovirus illnesses during infancy predict subsequent childhood wheezing. J Allergy Clin Immunol 2005; 116: 571-577.

128 Guilbert TW, Singh AM, Danov Z, et al. Decreased lung function after preschool wheezing rhinovirus illnesses in children at risk to develop asthma. J Allergy Clin Immunol 2011; 128: 532-538.

129 Jackson DJ, Gangnon RE, Evans MD, et al. Wheezing rhinovirus illnesses in early life predict asthma development in high-risk children. Am J Respir Crit Care Med 2008; 178: 667-672.

130 Kusel MMH, Kebadze T, Johnston SL, et al. Febrile respiratory illnesses in infancy and atopy are risk factors for persistent asthma and wheeze. Eur Respir J 2012; 39: 876-882.

131 Smit LA, Bouzigon E, Pin I, et al. 17q21 variants modify the association between early respiratory infections and asthma. Eur Respir J 2010; 36: 57-64.

132 Kerkhof M, Boezen HM, Granell R, et al. Transient early wheeze and lung function in early childhood associated with chronic obstructive pulmonary disease genes. J Allergy Clin Immunol 2014; 133: 68-76.

133 Smith LJ, McKay KO, van Asperen PP, et al. Normal development of the lung and premature birth. Paediatr Respir Rev 2010; 11: 135-142.

134 Gappa M, Stocks J, Merkus P. Lung growth and development after preterm birth: further evidence. Am J Respir Crit Care Med 2003; 168: 399.

135 Goldenberg RL, Hauth JC, Andrews WW. Intrauterine infection and preterm delivery. N Engl J Med 2000; 342: 1500-1507.

136 Stocks J, Hislop A, Sonnappa S. Early lung development: lifelong effect on respiratory health and disease. Lancet Respir Med 2013; 1: 728-742.

137 Jobe AH, Bancalari E. Bronchopulmonary dysplasia. Am J Respir Crit Care Med 2001; 163: 1723-1729.

138 Baraldi E, Filippone M. Chronic lung disease after premature birth. N Engl J Med 2007; 357: 1946-1955.

139 Coalson JJ. Pathology of new bronchopulmonary dysplasia. Semin Neonatol 2003; 8: 73-81.

140 Stern DA, Morgan WJ, Wright AL, et al. Poor airway function in early infancy and lung function by age 22 years: a non-selective longitudinal cohort study. Lancet 2007; 370: 758-764.

141 Blayney M, Kerem E, Whyte H, et al. Bronchopulmonary dysplasia: improvement in lung function between 7 and 10 years of age. J Pediatr 1991; 118: 201-206.

142 Narang I, Rosenthal M, Cremonesini D, et al. Longitudinal evaluation of airway function 21 years after preterm birth. Am J Respir Crit Care Med 2008; 178: 74-80.

143 Kotecha SJ, Edwards MO, Watkins WJ, et al. Effect of preterm birth on later FEV1: a systematic review and metaanalysis. Thorax 2013; 68: 760-766.

144 Vollsæter M, Røksund OD, Eide GE, et al. Lung function after preterm birth: development from mid-childhood to adulthood. Thorax 2013; 68: 767-776.

145 Cazzato S, Ridolfi L, Bernardi F, et al. Lung function outcome at school age in very low birth weight children. Pediatr Pulmonol 2013; 48: 830-837.

146 Doyle LW, Faber B, Callanan C, et al. Bronchopulmonary dysplasia in very low birth weight subjects and lung function in late adolescence. Pediatrics 2006; 118: 108-113.

147 Filippone M, Bonetto G, Cherubin E, et al. Childhood course of lung function in survivors of bronchopulmonary dysplasia. JAMA 2009; 302: 1418-1420.

148 Hacking DF, Gibson AM, Robertson C, et al. Respiratory function at age 8-9 after extremely low birth weight or preterm birth in Victoria in 1997. Pediatr Pulmonol 2013; 48: 449-455.

149 Fawke J, Lum S, Kirkby J, et al. Lung function and respiratory symptoms at 11 years in children born extremely preterm: the EPICure study. Am J Respir Crit Care Med 2010; 182: 237-245.

150 Lum S, Kirkby J, Welsh L, et al. Nature and severity of lung function abnormalities in extremely pre-term children at 11 years of age. Eur Respir J 2011; 37: 1199-1207.

151 Vom Hove M, Prenzel F, Uhlig HH, et al. Pulmonary outcome in former preterm, very low birth weight children with bronchopulmonary dysplasia: a case-control follow-up at school age. J Pediatr 2014; 164: 40-45.

152 Narayanan M, Beardsmore CS, Owers-Bradley J, et al. Catch-up alveolarization in ex-preterm children: evidence from ${ }^{3} \mathrm{He}$ magnetic resonance. Am J Respir Crit Care Med 2013; 187: 1104-1109.

153 Carraro S, Filippone M, Da Dalt L, et al. Bronchopulmonary dysplasia: the earliest and perhaps the longest lasting obstructive lung disease in humans. Early Hum Dev 2013; 89: Suppl. 3, S3-S5.

154 Gough A, Spence D, Linden M, et al. General and respiratory health outcomes in adult survivors of bronchopulmonary dysplasia: a systematic review. Chest 2012; 141: 1554-1567.

155 Consortium on Safe Labor, Hibbard JU, Wilkins I, et al. Respiratory morbidity in late preterm births. JAMA 2010; 304: 419-425. 
156 Paranjothy S, Dunstan F, Watkins WJ, et al. Gestational age, birth weight, and risk of respiratory hospital admission in childhood. Pediatrics 2013; 132: e1562-e1569.

157 Kotecha SJ, Dunstan FD, Kotecha S. Long term respiratory outcomes of late preterm-born infants. Semin Fetal Neonatal Med 2012; 17: 77-81.

158 Colin AA, McEvoy C, Castile RG. Respiratory morbidity and lung function in preterm infants of 32 to 36 weeks' gestational age. Pediatrics 2010; 126: 115-128.

159 Filippone M, Carraro S, Baraldi E. The term "asthma" should be avoided in describing the chronic pulmonary disease of prematurity. Eur Respir J 2013; 42: 1430-1431.

160 Global Initiative for Chronic Obstructive Lung Disease. Global Strategy for the Diagnosis, Management and Prevention of Chronic Obstructive Pulmonary Disease. www.goldcopd.org/uploads/users/files/GOLD_Report_ 2014_Jun11.pdf Date last updated: June 11, 2014.

161 Bush A. COPD: a pediatric disease. COPD 2008; 5: 53-67.

162 Stocks J, Sonnappa S. Early life influences on the development of chronic obstructive pulmonary disease. Ther $A d v$ Respir Dis 2013; 7: 161-173.

163 Lawlor DA, Ebrahim S, Davey Smith G. Association of birth weight with adult lung function: findings from the British Women's Heart and Health Study and a meta-analysis. Thorax 2005; 60: 851-858.

164 Canoy D, Pekkanen J, Elliott P, et al. Early growth and adult respiratory function in men and women followed from the fetal period to adulthood. Thorax 2007; 62: 396-402.

165 Barker DJ, Godfrey KM, Fall C, et al. Relation of birth weight and childhood respiratory infection to adult lung function and death from chronic obstructive airways disease. BMJ 1991; 303: 671-675.

166 Postma DS, Bush A, van den Berge M. Risk factors and early origins of chronic obstructive pulmonary disease. Lancet 2014 [In press DOI: 10.1016/S0140-6736(14)60446-3].

167 Martinez FD. The origins of asthma and chronic obstructive pulmonary disease in early life. Proc Am Thorac Soc 2009; 6: 272-277.

168 O'Reilly MA, Marr SH, Yee M, et al. Neonatal hyperoxia enhances the inflammatory response in adult mice infected with influenza A virus. Am J Respir Crit Care Med 2008; 177: 1103-1110.

169 Shi W, Warburton D. Is COPD in adulthood really so far removed from early development? Eur Respir J 2010; 35 : $12-13$.

170 Young RP, Hopkins R, Eaton TE. Forced expiratory volume in one second: not just a lung function test but a marker of premature death from all causes. Eur Respir J 2007; 30: 616-622.

171 Filippone M, Carraro S, Baraldi E. From BPD to COPD? The hypothesis is intriguing but we lack lung pathology data in humans. Eur Respir J 2010; 35: 1419-1420.

172 Bolton CE, Bush A, Hurst JR, et al. Are early life factors considered when managing respiratory disease? A British Thoracic Society survey of current practice. Thorax 2012; 67: 1110.

173 Auffray C, Adcock IM, Chung KF, et al. An integrative systems biology approach to understanding pulmonary diseases. Chest 2010; 137: 1410-1416.

174 Holt PG, Sly PD. Non-atopic intrinsic asthma and the "family tree" of chronic respiratory disease syndromes. Clin Exp Allergy 2009; 39: 807-811.

175 Vanfleteren LE, Kocks JW, Stone IS, et al. Moving from the Oslerian paradigm to the post-genomic era: are asthma and COPD outdated terms? Thorax 2014; 69: 72-79.

176 Bisgaard H, Bønnelykke K. Long-term studies of the natural history of asthma in childhood. J Allergy Clin Immunol 2010; 126: 187-197.

177 Sauer U, Heinemann M, Zamboni N. Genetics. Getting closer to the whole picture. Science 2007; 316: 550-551.

178 Agusti A, Sobradillo P, Celli B. Addressing the complexity of chronic obstructive pulmonary disease: from phenotypes and biomarkers to scale-free networks, systems biology, and P4 medicine. Am J Respir Crit Care Med 2011; 183: 1129-1137.

179 Wheelock CE, Goss VM, Balgoma D, et al. Application of 'omics technologies to biomarker discovery in inflammatory lung diseases. Eur Respir J 2013; 42: 802-825.

180 Carraro S, Giordano G, Reniero F, et al. Metabolomics: a new frontier for research in pediatrics. J Pediatr 2009; 154 : 638-644.

181 Carraro S, Giordano G, Reniero F, et al. Asthma severity in childhood and metabolomic profiling of breath condensate. Allergy 2013; 68: 110-117.

182 Fitzpatrick AM, Park Y, Brown LA, et al. Children with severe asthma have unique oxidative stress-associated metabolomic profiles. J Allergy Clin Immunol 2014; 133: 258-261.

183 Wang L, Tang Y, Liu S, et al. Metabonomic profiling of serum and urine by ${ }^{1} \mathrm{H}$ NMR-based spectroscopy discriminates patients with chronic obstructive pulmonary disease and healthy individuals. PLoS One 2013; 8: e65675.

184 Oresic M, Simell S, Sysi-Aho M, et al. Dysregulation of lipid and amino acid metabolism precedes islet autoimmunity in children who later progress to type 1 diabetes. J Exp Med 2008; 205: 2975-2984.

185 Romero R, Mazaki-Tovi S, Vaisbuch E, et al. Metabolomics in premature labor: a novel approach to identify patients at risk for preterm delivery. I Matern Fetal Neonatal Med 2010; 23: 1344-1359.

186 Baraldi E, Giuseppe G, Stocchero M, et al. Metabolomic profiling of the amniotic fluid predicts the risk of preterm delivery and BPD development. Eur Respir J 2014; 44: Suppl. 58, 274.

187 McEvoy CT, Jain L, Schmidt B, et al. Bronchopulmonary dysplasia: NHLBI Workshop on the Primary Prevention of Chronic Lung Diseases. Ann Am Thorac Soc 2014; 11: Suppl. 3, S146-S153.

188 Jackson DJ, Hartert TV, Martinez FD, et al. Asthma: NHLBI Workshop on the Primary Prevention of Chronic Lung Diseases. Ann Am Thorac Soc 2014; 11: Suppl. 3, S139-S145. 